\title{
CDX-2 immunostaining in primary and secondary ovarian carcinomas
}

\author{
L Tornillo, H Moch, P-A Diener, A Lugli, G Singer
}

J Clin Pathol 2004;57:641-643. doi: 10.1136/jcp.2003.013615

Aims: To assess the value of homeobox protein CDX-2 expression in the distinction between primary ovarian carcinomas and carcinomas metastatic to the ovary.

Methods: CDX-2 expression was assessed by immunohistochemistry in 120 serous, 68 endometrioid, 24 clear cell, and 16 mucinous carcinomas of the ovary. In addition, CDX-2 immunoreactivity was investigated in 20 metastases from adenocarcinomas to the ovary (15 of colorectal, two of gastric, one of appendiceal, one of pancreatic, and one of cervical origin) and their corresponding primary tumours.

Results: Almost all of the primary ovarian carcinomas lacked immunoreactivity for CDX-2. In contrast, 14 of the 16 metastases to the ovary from intestinal primaries showed CDX-2 immunoexpression.

Conclusion: CDX-2 is a useful marker for differentiating primary ovarian carcinoma from carcinomas metastatic to the ovary.

$\mathrm{T}$ he distinction between ovarian carcinomas and carcinomas metastatic to the ovary is important because the management and prognosis of these two entities are different. ${ }^{12}$ Morphologically, metastases to the ovary can be easily confused with primary ovarian carcinoma. ${ }^{12}$ Histological criteria ${ }^{12}$ and immunohistochemical markers ${ }^{34}$ were proposed for differential diagnosis, but no individual marker is specific. ${ }^{45}$

CDX-2 is the product of the Cdx-2 homeobox gene, which encodes a transcription factor that plays a role as a regulatory protein for the proliferation and differentiation of intestinal epithelial cells. ${ }^{6} \mathrm{CDX}-2$ expression was found in up to $100 \%$ of intestinal carcinomas. ${ }^{67}$ The reported prevalence of CDX-2 expression in primary ovarian carcinomas is inconsistent. In "non-mucinous" and serous carcinomas, two studies found a lack of immunostaining for CDX-2, ${ }^{67}$ whereas one study found CDX-2 immunoreactivity in $20 \%$ of endometrioid carcinomas. $^{8}$ In mucinous carcinomas, CDX-2 expression was detected in $20-100 \%$ of the tumours..$^{6-8}$

\footnotetext{
"The distinction between ovarian carcinomas and carcinomas metastatic to the ovary is important because the management and prognosis of these two entities are different ${ }^{\prime \prime}$
}

Based on these findings, we decided to investigate further the role of CDX-2 in primary ovarian carcinoma and to include metastases from distant carcinomas to the ovary, to assess the usefulness of CDX-2 as a marker for the distinction between primary ovarian carcinomas and metastases to the ovary.

\section{MATERIALS AND METHODS Tissue samples}

Our investigation included a tissue microarray with 212 primary ovarian carcinomas (120 serous, 68 endometrioid, and 24 clear cell subtypes), which was used in an earlier study. ${ }^{9}$ In addition, 16 formalin fixed, paraffin wax embedded tissue blocks of primary ovarian mucinous carcinomas and 20 metastases to the ovary with corresponding primaries were identified from the surgical pathology files of the Institute of Pathology of the University of Basel, Switzerland. Borderline tumours and lesions that usually do not pose a diagnostic problem, such as signet ring cell tumours, were excluded. The classification of ovarian carcinomas as primaries was based on the following criteria: (a) no patient history of a primary carcinoma elsewhere and (b) morphological criteria of primary ovarian carcinomas, as published previously. ${ }^{2}$ In the metastatic tumours that were selected for evaluation, the tumour of origin occurred simultaneously or preceded the ovarian tumour by a short period of time. All metastatic carcinomas fulfilled the morphological criteria of metastatic tumours to the ovary, as described previously. ${ }^{2}$

\section{Immunohistochemistry}

After dewaxing, tissue sections $(5 \mu \mathrm{m})$ were heated in a microwave oven in citrate buffer $(\mathrm{pH} 6.0)$ at $98^{\circ} \mathrm{C}$ for 30 minutes, to facilitate antigen retrieval. The slides were then incubated overnight with the monoclonal antibody against CDX-2 (prediluted CDX-2-88; Biogenex, San Ramon, California, USA). The reaction product was visualised using the $\mathrm{ABC}$ Elite vector system and 3,3' diaminobenzidine as a chromogen. Sections were dehydrated, mounted, and counterstained with haematoxylin. All procedures were performed according to the manufacturer's protocol. The negative control was omission of the primary antibody. Nuclear staining was scored in a semiquantitative manner as follows: 0 , no staining; $1+,<25 \% ; 2+, 26-75 \% ; 3+,>75 \%$.

\section{RESULTS}

Table l summarises the immunostaining results in the ovarian tumours. Some tumours showed a fine or focally coarse granular cytoplasmic staining pattern (fig 1). Occasional cytoplasmic staining was seen in normal colonic epithelium, inflammatory cells, and macrophages (fig 1). CDX-2 immunoreactivity was almost absent in all primary ovarian carcinomas with the exception of one mucinous carcinoma, which showed immunostaining in less than $25 \%$ of the tumour cells $(1+)$. Fourteen (all moderately differentiated adenocarcinomas) of the 16 (two additional poorly differentiated adenocarcinomas) metastatic tumours to the ovary of intestinal origin, in addition to their primaries, showed immunoreactivity for CDX-2 in over $75 \%(3+)$ of the tumour cells (fig 1). Metastases from gastric, pancreatic, and cervical adenocarcinomas were negative for CDX-2. Morphologically, metastases from the intestinal carcinomas 
Table 1 Staining for CDX-2 in primary ovarian carcinomas and metastatic carcinomas to the ovary

\begin{tabular}{|c|c|c|c|}
\hline Lesions & $\begin{array}{l}\text { No. of } \\
\text { cases }\end{array}$ & $\begin{array}{l}\text { No. of CDX-2 } \\
\text { positive cases }\end{array}$ & $\begin{array}{l}\text { CDX-2 } \\
\text { immunoreactive } \\
\text { tumours (\%) }\end{array}$ \\
\hline Serous carcinoma (TMA) & 129 & 0 & $0 \%$ \\
\hline $\begin{array}{l}\text { Endometrioid carcinoma } \\
\text { (TMA) }\end{array}$ & 68 & 0 & $0 \%$ \\
\hline $\begin{array}{l}\text { Clear cell carcinoma } \\
\text { (TMA) }\end{array}$ & 24 & 0 & $0 \%$ \\
\hline Mucinous carcinoma (CS) & 16 & $1^{*}$ & $0 \% *$ \\
\hline $\begin{array}{l}\text { Metastatic carcinoma from } \\
\text { (CS) }\end{array}$ & & & \\
\hline Colont & 15 & $13 \ddagger$ & $93 \%$ \\
\hline Appendix & 1 & 1 & $100 \%$ \\
\hline Stomach & 2 & 0 & $0 \%$ \\
\hline Pancreas & 1 & 0 & $0 \%$ \\
\hline Cervix & 1 & 0 & $0 \%$ \\
\hline \multicolumn{4}{|c|}{$\begin{array}{l}\text { * }<25 \% \text { of tumour cells; } \uparrow 13 \text { moderately and } 2 \text { poorly differentiated } \\
\text { adenocarcinomas. The ovarian tumours showed a predominant } \\
\text { "pseudoendometrioid" pattern in all } 13 \text { cases, with areas of mucinous } \\
\text { histology in } 3 \text { cases. Two ovarian metastases consisted of the same poorly } \\
\text { differentiated adenocarcinoma, as in their colonic primaries. } \ddagger \text { The two } \\
\text { poorly differentiated adenocarcinomas were negative for CDX-2. } \\
\text { CS, conventional slides; TMA, tissue microarray. }\end{array}$} \\
\hline
\end{tabular}

predominantly mimicked endometrioid and focally mucinous ovarian carcinomas.

\section{DISCUSSION}

Metastases from intestinal carcinomas can be mistaken for endometrioid, mucinous, and rarely clear cell subtypes of primary ovarian carcinoma. In fact, reports show that more than two thirds of metastatic intestinal carcinomas can be initially misinterpreted as primary ovarian carcinomas. ${ }^{10}$ In addition, recent studies indicate that most mucinous carcinomas occurring in the ovary are in fact metastases, mostly from the gastrointestinal tract. ${ }^{1}$

Immunohistochemical markers that are in use for the distinction between primary and metastatic ovarian carcinomas include cytokeratin 7 , cytokeratin 20 , Dpc4, and $\beta$ catenin, ${ }^{3}{ }^{4}$ although no individual marker is specific. ${ }^{3}{ }^{4}$ Therefore, primary ovarian carcinomas and metastatic carcinomas to the ovary should be identifiable by a distinct pattern of markers or by more reliable markers.

\begin{abstract}
"We found no immunoreactivity in endometrioid or mucinous subtypes of ovarian carcinoma, either in the tissue microarray or in the 16 conventional slides"
\end{abstract}

The detailed distribution of CDX-2 in a variety of tumours has been reported previously. ${ }^{6-8}$ Most carcinomas that expressed CDX-2 in almost $100 \%$ of cases were of intestinal origin. Lower rates were reported for gastric and pancreatic carcinomas. ${ }^{6} 7$ Primary "non-mucinous" ${ }^{\prime 6}$ and serous ${ }^{7}$ ovarian carcinomas lacked CDX-2 immunoexpression. These findings are in complete agreement with our results. In contrast, however, we found no immunoreactivity in endometrioid or mucinous subtypes of ovarian carcinoma, either in the tissue microarray or in the 16 conventional slides (table 1). The previously reported high rates of CDX-2 immunoreactivity in endometrioid and especially in mucinous ovarian carcinomas $^{6-8}$ might in part be explained by a misclassification of metastases as ovarian primaries. Concerns that data obtained from tissue microarrays, as in part of this study, would not be representative were investigated extensively in earlier publications. ${ }^{11}$ In fact, all previous immunohistochemical findings using large tissue samples could be fully reproduced in tissue microarray studies. ${ }^{11}$

Although CDX-2 appears to be an excellent marker for metastases to the ovaries from intestinal carcinomas, it should be noted that poorly differentiated intestinal carcinomas may lose their CDX-2 expression and that rare primary ovarian tumours may be focally positive for CDX-2, conceivably as the result of a form of intestinal differentiation. In conclusion, this antibody represents a useful additional marker for the distinction between primary ovarian carcinomas and metastatic carcinomas to the ovary.
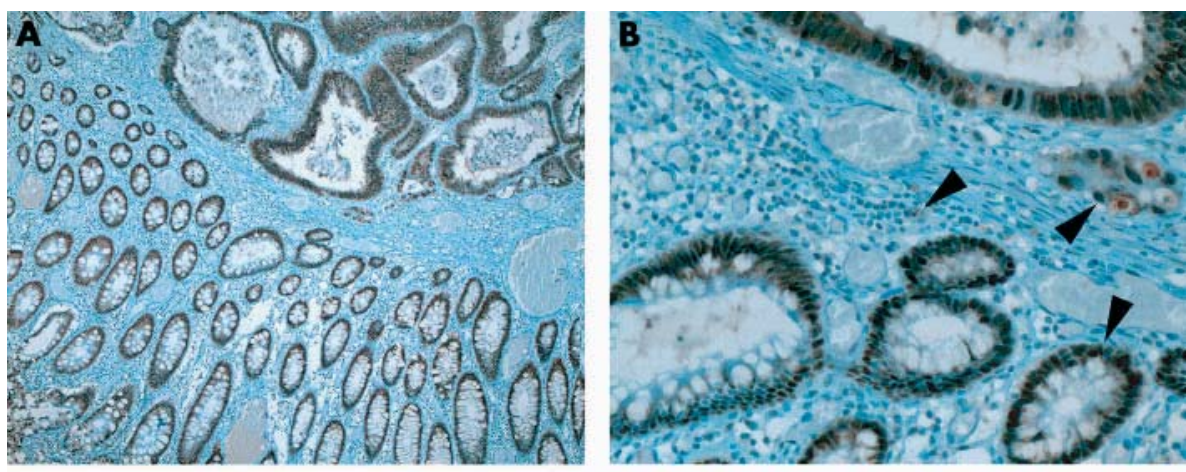

Figure 1 Nuclear staining for CDX-2 in colorectal carcinoma with adjacent normal colonic mucosa $(A$, original magnification, $\times 50$; $B$, original magnification, $\times 200$ ) and ovarian metastasis $(C$, original magnification, $\times 50$; D, original magnification, $\times 200$ ) Note the cytoplasmic staining seen in some epithelial, inflammatory, and neoplastic cells (arrowheads).
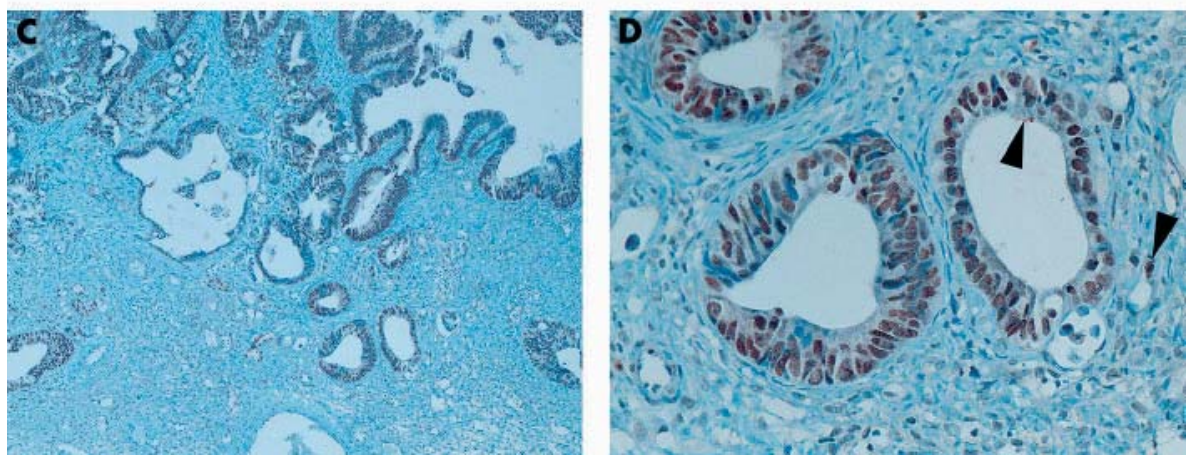


\section{Take home messages}

- The CDX-2 antibody is a useful additional marker for differentiating primary ovarian carcinoma from carcinomas metastatic to the ovary

- Almost all of the primary ovarian carcinomas lacked immunoreactivity for CDX-2, whereas 14 of the 16 metastases to the ovary from intestinal primaries showed CDX-2 immunoexpression

\section{ACKNOWLEDGEMENTS}

The authors are most grateful to Mrs R Epper, Mrs S Grieshaber, and the technical staff of the Institute of Pathology of the University of Basel for their excellent technical support.

\section{Authors' affiliations}

L Tornillo, H Moch, A Lugli, G Singer, Institute of Pathology, University of Basel, Schoenbeinstrasse 40, 4031 Basel, Switzerland

P-A Diener, Institute of Pathology, Cantonal Hospital, St Gallen, Switzerland

Correspondence to: $\operatorname{Dr} G$ Singer, Institute of Pathology, University of Basel, Schoenbeinstrasse 40, 4031 Basel, Switzerland; gsinger@uhbs.ch

Accepted for publication 22 October 2003

\section{REFERENCES}

1 Seidman JD, Kurman RJ, Ronnett BM. Primary and metastatic mucinous adenocarcinomas in the ovaries: incidence in routine practice with a new approach to improve intraoperative diagnosis. Am J Surg Pathol 2003;27:985-93.

2 Lee KR, Young RH. The distinction between primary and metastatic mucinous carcinomas of the ovary: gross and histologic findings in 50 cases. Am J Surg Pathol 2003;27:281-92.

$3 \mathrm{Ji} \mathrm{H}$, Isacson C, Seidman JD, et al. Cytokeratins 7 and 20, Dpc4, and MUC5AC in the distinction of metastatic mucinous carcinomas in the ovary from primary ovarian mucinous tumors: Dpc4 assists in identifying metastatic pancreatic carcinomas. Int J Gynecol Pathol 2002;21:391-400.

4 Chou YY, Jeng YM, Kao HL, et al. Differentiation of ovarian mucinous carcinoma and metastatic colorectal adenocarcinoma by immunostaining with beta-catenin. Histopathology 2003;43:151-6.

5 Park SY, Kim HS, Hong EK, et al. Expression of cytokeratins 7 and 20 in primary carcinomas of the stomach and colorectum and their value in the differential diagnosis of metastatic carcinomas to the ovary. Hum Pathol 2002;33:1078-85.

6 Werling RW, Yaziii H, Bacchi CE, et al. CDX2, a highly sensitive and specific marker of adenocarcinomas of intestinal origin: an immunohistochemical survey of $\mathbf{4 7 6}$ primary and metastatic carcinomas. Am J Surg Pathol 2003;27:303-10.

7 Barbareschi M, Murer B, Colby TV, et al. CDX-2 homeobox gene expression is a reliable marker of colorectal adenocarcinoma metastases to the lungs. Am J Surg Pathol 2003;27:141-9.

8 Moskaluk CA, Zhang H, Powell SM, et al. Cdx2 protein expression in normal and malignant human tissues: an immunohistochemical survey using tissue microarrays. Mod Pathol 2003;16:913-19.

9 Schraml P, Schwerdiffeger G, Burkhalter F, et al. Combined array comparative genomic hybridization and tissue microarray analysis suggest PAK 1 at 1 lq13.5-q14 as a critical oncogene target in ovarian carcinoma. Am J Pathol 2003;163:985-92.

10 Lash RH, Hart WR. Intestinal adenocarcinomas metastatic to the ovaries. A clinicopathologic evaluation of 22 cases. Am J Surg Pathol 1987;1 1:11 14-21.

11 Torhorst J, Bucher C, Kononen J, et al. Tissue microarrays for rapid linking of molecular changes to clinical endpoints. Am J Pathol 2001;159:2249-56. 